\title{
Evaluation of Urban Residence, Employment and Transportation Mode in Beijing
}

\author{
Peng XIAO \\ China Urban Sustainable Transportation Research Center (CUSTReC) \\ China Academy of Transportation Sciences \\ Beijing, China \\ e-mail: pengxiao@motcats.com.cn
}

\begin{abstract}
The relationship between urban landuse and urban transportation is the eternal topic of urban development. The integration development of urban landuse and urban transportation determines the comprehensive carrying capacity of a city. The spatial statistics and the questionnaire survey method are used in this paper. Then the interactive relationship between urban spatial structure and the transportation development mode for Beijing is analyzed. On this basis, the matching relationship between Beijing urban residential land, employment land and urban transportation development mode is evaluated. The internal factors, the external factors and the interaction features of urban landuse and transportation of Beijing are demonstrated. Finally, the related-counter measures about the job housing balance and the development mode of urban traffic in Beijing are put forward.
\end{abstract}

Keywords-residence; employment; transportation mode; analysis and evaluation

\section{INTRODUCTION}

Urban landuse is the source of travel demand. The land of Residence and employment is a direct source of travel demand. The relationship between residence, employment and transportation is shown in figure 1-1. From the aspect of the urban landuse, urban residence and employment landuse can be abstracted as two points, and transportation is the connecting line for residence and employment landuse. This is the static relations of the material level. From the intrinsic motivation, the relationship between residence and employment is people in essence. Transportation is the carrier for the people from the place of residence to the employment place. Residence land and employment land are the two basic elements of urban landuse. The spatial relationship between residence and employment landuse largely determines the characteristics and efficiency of urban transportation. A large number of studies show that the complex interactions of landuse and urban transportation revealed in multiple levels of urban planning, strategy, construction, control and implementation.

In the past half century, foreign scholars have done a lot of research on the relationship between urban spatial structure and travel demand. As the two core variables of the urban spatial structure, residence and employment have been paid more attention. As early as in 1960s, Kain proposed the spatial mismatch hypothesis and elaborated the spatial mismatch between work position and the staff residence position in quantity and the quality. Thereafter, the concept of "jobs-housing balance" is gradually defined in the new city development movement. In 1998, Levinson found that the trip distance is relatively short when living a relatively adequate area of work or working in a more adequate housing area, was relatively from the case study in Washington. In 2001, Schwanen also found that the main reason for increasing commuting distance was the spatial imbalance of employment and residence.

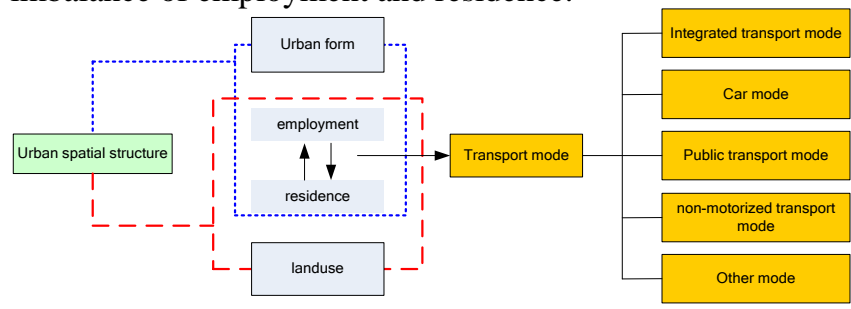

Figure 1. Residence, employment and transportation

On the domestic, in 2005 and 2006, Zhou Suhong used the concept of entropy to measure the spatial equilibrium between residence and employment with travel demand in Guangzhou, and found that there was consistency between the two elements. In 2007, Li Qiang studied the travel demand of Huilongguan and Tiantongyuan area in Beijing. He found that there were a lot of central travel demands at fixed time every day, increasing urban transportation congestion and extended the commuting time and distance due to Job-housing separation. In 2007, Song Jinping and Zhang Enru also believed that Beijing has appeared the problems of the housing and employment spatial mismatch, which caused the increase of low-income commuting time cost and the economic cost, and lead to traffic congestion, social isolation and other social problems along with the large scale development of residential suburbanization.

This paper evaluates the match level between urban residence land, employment land and transportation development mode and interaction mechanism among them in Beijing. Then suggestions on job-housing balance and transportation mode for Beijing are put forward. The aim is to support urban planning and transportation planning, even major transportation infrastructure layout and promote the sustainable development of Beijing. 


\section{DATA PROCESSING AND ANALYSIS}

\section{A. Beijing Urban Transportation Supply}

In recent years, the increasing transportation construction investment has brought the rapid growth of urban roads in Beijing. Taking 2005 as the base year, the total mileage of urban streets reaches 6223 kilometers at the end of 2015, with an average annual increase of $11 \%$. The total mileage of highway reaches 21885 kilometers at the end of 2015, with an average annual increase of $9 \%$. But compared with the developed cities, current urban road density and landuse rate of Beijing are still significantly lower. Urban bus and tram vehicles reaches 21716 by the end of 2015. Wherever Times is specified, Times Roman or Times New Roman may be used. If neither is available on your word processor, please use the font closest in appearance to Times. Avoid using bitmapped fonts if possible. True-Type 1 or Open Type fonts are preferred. Please embed symbol fonts, as well, for math, etc.

TABLE I. VARIOUS INDICATORS OF BUS AND TRAM IN 2011-2015

\begin{tabular}{|c|c|c|c|c|c|}
\hline Year & $\mathbf{2 0 1 1}$ & $\mathbf{2 0 1 2}$ & $\mathbf{2 0 1 3}$ & $\mathbf{2 0 1 4}$ & $\mathbf{2 0 1 5}$ \\
\hline Routes(number) & 740 & 779 & 813 & 877 & 876 \\
\hline Length(km) & 19338 & 19547 & 20575 & 20347 & 20315 \\
\hline Vehicles(units) & 21575 & 22146 & 22486 & 24083 & 24347 \\
\hline
\end{tabular}

\section{B. Beijing Urban Travel Demand}

In 2015, the per capita GDP of Beijing reaches 106284 Yuan. Most of family in Beijing has enough money to buy a private car. At the end of 2015, the motor vehicle ownership of Beijing reaches 5.62 million and the private cars reaches 4.4 million which are more than 0.81 million and 0.66 million separately in 2010. In lines with international practices of 10 cars per hundred households, average per hundred households family in Beijing has 25.8 motor vehicles and private car 14.6 private cars. It means that Beijing has begun to enter the automobile society. In the future, Beijing will face more and more serious transport pressure. With the rapid urbanization, more and more people come into Beijing. Until the end of 2015, the resident population of Beijing has reached 21.70 million. In addition, mobile population is also increasing rapidly. A number of private cars are used for commuting which results in the surging of motor travel demand.

TABLE II. VEHICLE OWNERSHIP IN 2011-2015

\begin{tabular}{|c|c|c|c|}
\hline year & $\begin{array}{c}\text { Motor vehicle } \\
\text { ownership } \\
\text { (ten thousand) }\end{array}$ & $\begin{array}{c}\text { Private vehicle } \\
\text { ownership } \\
\text { (ten thousand) }\end{array}$ & $\begin{array}{c}\text { Private car } \\
\text { ownership } \\
\text { (ten thousand) }\end{array}$ \\
\hline 2011 & 498.3 & 389.7 & 286.2 \\
\hline 2012 & 520 & 407.5 & 298.2 \\
\hline 2013 & 543.7 & 426.5 & 311 \\
\hline 2014 & 559.1 & 437.2 & 316.5 \\
\hline 2015 & 561.9 & 440.3 & 316.5 \\
\hline
\end{tabular}

\section{Beijing Residence and Employment}

1) Spatial pattern of residence land:

According to the survey in 2015, the resident population distribution in Beijing is a circle layered outward radiation, namely gathering from the second, third ring road to outside the fourth ring road. The population outside the fifth ring road is more than 10.98 million that accounts for $51 \%$ of the whole city. The characteristics of the spatial pattern of residential land are described from the following aspects.

a) Rapid expansion of built-up area:

From 90s of the last century, Beijing began to experience such a process that large-scale new residence areas appeared in the suburbs. Some residence areas such as Huilongguan area with 300 thousand planning population could be called "small town" for large population and big range. Along with the movement of "built town", the built-area of Beijing expands rapidly from $397 \mathrm{~km}^{2}$, to $490 \mathrm{~km}^{2}$ in 1999 , to $1268 \mathrm{~km}^{2}$ in 2014.

\section{b) Distributing group layout:}

In 50s of the last century, the decentralized group layout mode of Beijing was put forward. So it could be said that the residential suburbanization is already determined in 50s. Current urban planning of Beijing was approved in 1994. The main content include: Downtown area with more than $320 \mathrm{~km} 2$ is the core area of urban construction. Political and cultural function should be mainly focused, but the residence land should be weakened in this area. There are 10 marginal groups such as Beiyuan, Jiuxianqiao, Nanyuan, Shijingshan, Qinghe and so on, which are separated by green belt. And then 14 satellite cities will be built around Beijing. 40 towns are layout around 14 satellite cities. There are two strategies in Beijing urban planning. The first is that urban should extend outside the core area. The second is residential suburbanization that means to develop Suburban County. Based on this strategy Beijing built a lot of residence in the marginal groups and satellite cities such as Wangjing, Huilongguan, etc.

\section{c) Sprawl expansion of residential landuse:}

In the past 20 years, the most obvious change in Beijing is residential suburbanization. The rapid development of urban transportation and communication conditions which shorten the distance between the suburbs and the downtown and change the traditional concept on suburb. House in suburb with relatively lower prices has more competitive advantage than that in downtown.

Beijing came into the stage of residential suburbanization in 1980s. But population migration is mainly in the edge of the central urban area, and the residence construction area is basically within the third ring road. In the 1990s, the residential suburbanization accelerated to the fourth ring road and then outside of the fifth ring road later, such as large residence areas of Wangjing, Tiantongyuan, Huilong and so on. Since the beginning of the new century, the expanding of residence area construction speeds up. For example, the new real estate within the fourth ring road in 2001 accounts for $51.9 \%$. That outside of the fourth ring road accounts for $48.1 \%$. But in 2004 the proportion of new real 
estate within the fourth ring road declines to $47 \%$. However the new real estate outside of the fourth ring road rises to $53 \%$ which accounts for $31.1 \%$ outside of the fifth ring road.

2) Spatial pattern of employment land:

As the urban center, the old city is still the gathering area of political, cultural, economic, transportation, tourism and other functions in Beijing at present. Various types of landuse are mixed in space. Government administrative office facilities mainly focus within the third ring road including Xicheng District and Dongcheng District, highly concentrated within the third ring road and north of Chang'an Avenue. Historical and cultural relics are mainly concentrated around the central axis. Large-scale cultural facilities most locate between the northwest second and third ring road and near Asian Sports Village and the Olympic Village. Business office functions gather significantly which mainly locate in Chaoyang District and Haidian District, followed by Xicheng District and Dongcheng District. Urban commercial service function mainly distributes along the ring road and the subject of commercial outlets is within the second ring road.

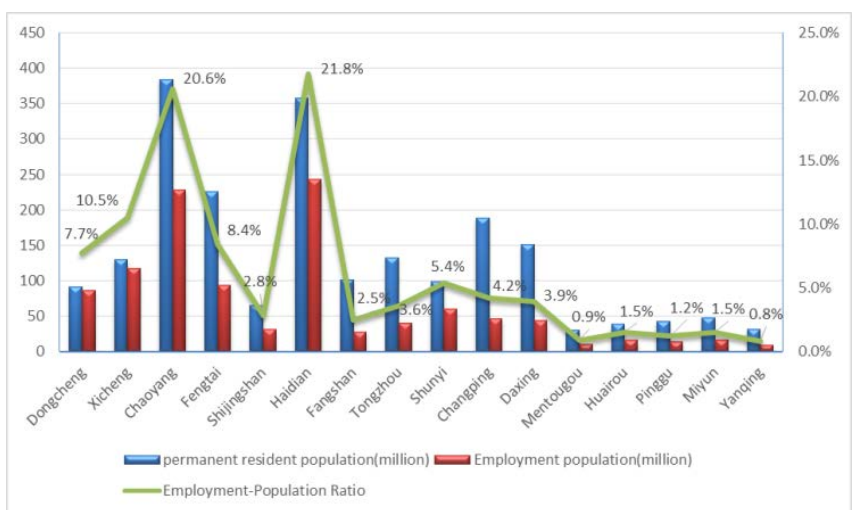

Figure 3. Permanent resident population and employment population of Beijing in 2013

Because of different conditions and development, especially poor infrastructures of most of the marginal groups, it is difficult to play the role of share population and functions of central urban area. So the single residence function landuse is developed in the marginal groups. This phenomenon is more serious in north than in south. Since the infrastructure is poor, transportation congestion is obvious. From the perspective of industrial structure, Beijing has entered into the stage of the third industry. Employment population and landuse are mainly in Beijing urban function development zone, especially in Chaoyang, Haidian District.

3) Spatial dislocation of residence and employment:

Spatial dislocation of residence and employment in Beijing has two forms. The first one is that urban internal spatial structure is not reasonable, since there is job-housing imbalance in old urban area. But this phenomenon is not obvious for small administrative region unit. The second one is the development of residential suburbanization. More and more people buy house located on the outskirts of the city. Due to the single residence function in the new suburban development area and the main business, financial services, government agencies, recreational facilities, hospitals, schools, parks which are still concentrated in the urban areas, people have to go to the downtown for jobs and services. Then the second spatial structure unreasonable is formed. Since the administrative region unit is larger, it generate big effect for trip mode choice, commute time and cost which result in the rising of transportation congestion external cost.

A questionnaire survey was carried out in six districts and Changping, Shunyi district. Investigating area is mainly in the six districts. Nonlocal personnel being investigated accounts for $48.7 \%$.

TABLE III. JOB-HOUSING RELATIONSHIP OF INVESTIGATION

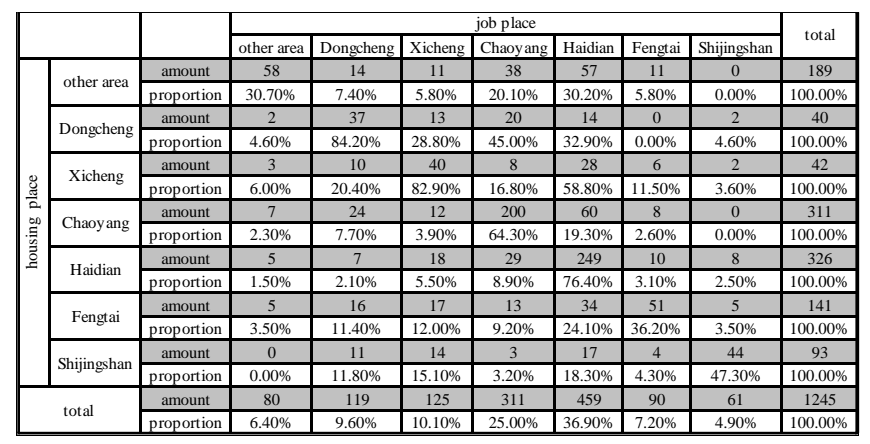

Through the commuting flows in different region, the proportion of residents work nearby is low. It is more than $53 \%$ (within the district). There are only three districts Haidian, Chaoying and whose proportion is more than $50 \%$. It means that local commute population proportion outside these districts is low. One reason is district area is large of these districts. Another reason is that the chance of residence and jobs are better. The trip volume proportion from outside of the internal six districts to the six districts accounts for $69.3 \%$ and Converse trip volume proportion is only $17.9 \%$. It means that the old urban area is still the main employment areas. In general, the job-housing balance in the six districts is better than that in the suburbs. The centripetal flow is the main commute direction. But there is also a certain percentage of the reverse commute. It indicates that the spatial organization mode of job-housing balance is gradually evolving.

Commuting time is the important indicator to measure the job-housing balance. From the view of commuting time, the commuting time in Beijing is long overall. The average commuting time is 57.53 minutes in Beijing by the survey statistics. And according to the US Census Bureau data, American daily commuting time is 25.1 minutes in 2005. The commuting time of Philadelphia area is 38.3 minutes that is the longest one in US. The second is New York area whose commuting time is 34.2 minutes. Compared with major cities in the United States, the commuting time is longer in Beijing.

TABLE IV. TRIP Distance AND TRIP Mode ChOICE 


\begin{tabular}{|c|c|c|c|c|c|c|c|c|}
\multirow{2}{*}{$\begin{array}{c}\text { trip } \\
\text { distance }\end{array}$} & \multicolumn{10}{|c|}{ trip mode(\%) } \\
\cline { 2 - 9 } & car & taxi & $\begin{array}{c}\text { urban } \\
\text { rail }\end{array}$ & BRT & BUS & $\begin{array}{c}\text { Unit } \\
\text { shuttle }\end{array}$ & bicycle & walk \\
\hline$<1 \mathrm{~km}$ & 1.73 & 0.94 & 0.39 & 1.49 & 10.31 & 0.08 & 8.81 & 72.23 \\
\hline $1-2 \mathrm{~km}$ & 5.11 & 3.07 & 2.99 & 3.38 & 32.57 & 0.31 & 24.31 & 23.05 \\
\hline $2-5 \mathrm{~km}$ & 8.73 & 7.95 & 11.41 & 5.51 & 45.55 & 0.24 & 14.08 & 1.89 \\
\hline $5-10 \mathrm{~km}$ & 11.17 & 7.47 & 28.09 & 6.14 & 37.61 & 0.31 & 3.7 & 0.08 \\
\hline $10-20 \mathrm{~km}$ & 15.42 & 5.04 & 46.11 & 5.74 & 19.98 & 0.55 & 1.02 & 0.08 \\
\hline$>20 \mathrm{~km}$ & 17.78 & 4.01 & 51.46 & 6.85 & 11.72 & 0.71 & 0.24 & 0.16 \\
\hline
\end{tabular}

Trips which the commuting time is less 30 minutes account for $32.8 \%$, 30-45 minutes account for $16.7 \%$, 45-60 minutes account for $22.5 \%$, 60-90 minutes account for $18.8 \%$,more than 90 minutes account for $9.1 \%$ among 1245 questionnaires. Thus, there are only about 33\% residents of Beijing whose commuting time is less 30 minutes. In general, the job-housing unbalance problem is very prominent in Beijing.

From the view of commuting distance, the main mode is bus within $5 \mathrm{~km}$. The main mode is urban rail when the commuting distance is more than $10 \mathrm{~km}$. the proportion of car trip which includes car and taxi is close to bus when the commuting distance is between $10 \mathrm{~km}$ and $20 \mathrm{~km}$. When the commuting distance is more $20 \mathrm{~km}$, the car trip amount is more bus trip.

\section{ANALYSIS AND EVULATION}

\section{A. Method}

City administrative districts are taken as the unit for the matching analysis between residence, employment and transport of Beijing. The premise assumption is set that if the job-housing tends to balance internal each city districts, then commuting trip will be finished internal city district. It also means that commuting trip cross different districts is lower and the total urban transport pressure is reduced. The analysis of job-housing balance can be carried out from two aspects of total amount and structure. The former is to measure the total balance between employment positions and the total population of each district. The latter is to analyze the structure balance between the employment position and the population. Due to the limited data, this section is mainly to detect the total balance. So the deviation indicator of job-housing is established and the calculation mode is below.

$$
Z_{i j}=\frac{Y_{i j} / Y_{i}}{R_{i j} / R_{i}}
$$

$Z_{i j}$ : deviation indicator of job-housing; $Y_{i j}$ : The employment population for I year in J district; $Y_{i}$ : the whole district employment population of the I year; $R_{i j}$ : The residence population for I year in $\mathrm{J}$ district; $R_{i}$ : the whole district residence population of the I year.

If the deviation indicator equal to 1 , it shows that the jobhousing in this district is relatively balanced. If the deviation indicator is greater than 1 or less than 1 , it shows that the job-housing in this district is imbalance. When the deviation indicator is greater than 1 , it means that employment population is larger than residence population and this area has stronger employment function, otherwise residential functions dominated.

\section{B. Evaluation Result}

The template is used to format your paper and style the text. All margins, column widths, line spaces, and text fonts are prescribed; please do not alter them. You may note peculiarities. For example, the head margin in this template measures proportionately more than is customary. This measurement and others are deliberate, using specifications that anticipate your paper as one part of the entire proceedings, and not as an independent document. Please do not revise any of the current designations.

The residence and employment population data is got from Beijing statistical yearbook and other materials. At first the spatial deviation indicators in different function areas are computed by using above mode. Then the influence of jobhousing on transportation of the function area is analyzed.

1) Core area of the capital function:

The core area of capital function includes Xicheng District, and Dongcheng District. The deviation indicators of job-housing in the two districts are shown in TABLE V.

TABLE V. DEVIATION INDICATORS OF JOB-HOUSING IN CORE AREA OF THE CAPITAL FUNCTION

\begin{tabular}{|c|c|c|}
\hline Dongcheng & Xicheng & Average \\
\hline 1.406374 & 1.458329 & 1.432352 \\
\hline
\end{tabular}

As can be seen from the TABLE V, the deviation indicators of job-housing in the core areas of the capital function are both greater than 1 . It shows that the proportion of employment population is more than the one of residence population. The employment function is stronger than the residence function. From the view of urban transport, these districts are the attraction areas of travel demand. Due to the mismatch of job-housing in the core area of capital function, coupled with limited road resources, the urban transport congestion problem is serious.

2) Urban functional expanding area:

The Urban functional expanding area includes Haidian District, Chaoyang District, Fengtai District and Shijingshan District. The deviation indicators of job-housing in the four districts are shown in TABLE VI.

TABLE VI. DEVIATION INDICATORS OF JOB-HOUSING IN URBAN FUNCTIONAL EXPANDING AREA

\begin{tabular}{|c|c|c|c|c|}
\hline Haidian & Chaoyang & Fengtai & Shijingshan & Average \\
\hline 0.8164 & 1.0512 & 0.8919 & 0.8598 & 0.9188 \\
\hline
\end{tabular}

There is a large number of living and working population in Beijing urban function area. Many people who work at the core area of capital function lives in Beijing urban function area. But there are few jobs relative to other areas of Beijing. As can be seen from the TABLE VI, the deviation indicators of job-housing in Chaoyang district is 1.051223 which is close to the balance level. The proportion of residence proportion is larger than the one of employment in other two 
districts which is the source of commuting transport expect Haidian district. Since there are many colleges in Haidian district, amount of student trip are high that does not affect the transport basically.

\section{3) New urban development area:}

The new urban development area includes Changping District, Shunyi District, Tongzhou District, Shijingshan District and Daxing District. The deviation indicators of jobhousing in the five districts are shown in TABLE VII.

TABLE VII. DEVIATION INDICATORS OF JOB-HOUSING IN NEW URBAN DEVELOPMENT AREA

\begin{tabular}{|c|c|c|c|c|c|}
\hline Changping & Shunyi & Tongzhou & Daxing & Fangshan & Average \\
\hline 0.8904 & 0.8904 & 0.8802 & 0.9868 & 0.928 & 0.929 \\
\hline
\end{tabular}

Most of the new urban development area belongs to the suburbs of Beijing. After years of urban construction and real estate development, the residence function is stronger than employment function in this area. Even in some areas the lying city feature is obvious, such as Tongzhou. Due to the lack of jobs in new urban development area, there is a large number of commuting transport and the tide transport congestion is very significant.

4) Ecological conservation area:

The ecological conservation area includes Mentougou District, Yanqing District, Huairou District, Miyun District and Pinggu District. The deviation indicators of job-housing in the five districts are shown in TABLE VIII.

TABLE VIII. DEVIATION INDICATORS OF JOB-HOUSING IN ECOLOGICAL CONSERVATION AREA

\begin{tabular}{|c|c|c|c|c|c|}
\hline Mentougou & Yanqing & Huairou & Miyun & Pinggu & Average \\
\hline 0.9364 & 1.0749 & 1.1314 & 0.9925 & 1.0378 & 1.0351 \\
\hline
\end{tabular}

Since the distance between Mentougou district and downtown is relatively close, the lying city features is obvious. Other districts are far away from the urban area and their connection to downtown is loose. Along with the industry "from two into three" strategy in Beijing, a lot of second industries migrate from urban central area to the ecological conservation area result in there are enough jobs in these areas. So the job-housing balance is matched. There is little transport congestion in these areas.

Through the evaluation and analysis on each district, the unbalanced area of job-housing in Beijing is large. The employment function is obvious in core area of capital function. Most of districts in urban functional expanding area and new urban development area have strengthened residence function. Due to long distance to the downtown and enough jobs, the job-housing balance is well in the ecological conservation area.

\section{CONCLUSION}

Mismatch of job-housing in space results in an increase of the cross commuting trip. Some other transport features will change bad, for example increasing average trip time and trip distance. Then the transport structure tends to be reasonable that make the transport congestion, transport safety and environmental population more and more serious. According to the evaluation, some suggestions for Beijing are put forward: Optimizing the residential function structure of central urban area, implementing the coordinated development of multi urban centers, promoting belt type balance of job-housing in south city, constructing three key new town of Tongzhou, Shunyi and Yizhuang, building a comprehensive transportation system to adapt to the trend of suburbanization and Improve the composite rapid transit system among different functional areas.

\section{ACKNOWLEDGMENT}

This research has been funded by National Natural Science Foundation Project (project number: 41471459).

\section{REFERENCES}

[1] Abbas, K.A. \& Bell, M.G.H., 1994. System Dynamics Applicability to Transportation Modeling, Transportation Research.

[2] Prastacos, P., 1986.Anintegrated landuse-transportation model for the SanFrancisco region: 1. Design and mathematical structure. Environment and Planning18A, pp. 307-322.

[3] Southworth, F., 1995. A Technical Review of Urban LandUseTransportation Modelsas Tools for Evaluating Vehicle Reduction Strategies, ResearchReportORNL-6881, OakRidgeNational. Laboratory, OakRidge, TN.

[4] Wegner, M., Fuurst, F., 1999. Landuse transport interaction: state of theart. Deliverable of the project TRANSLAND of the $4^{\text {th }}$ RTD Framework Programme of the European Commission.

[5] Kim, T. J., 1983. A combined landuse-transportation model when zonal travel demand is endogenously determined. Transportation Research17B, 449-462.

[6] Kim, T. J., Rho, J. H., Suh, S., 1989. Integrated Urban Systems Modeling: Theory and Applications.Kluwer Academic Publishers, Dordrecht, The Netherlands.

[7] Miller, H. J., Storm, J. D., 1996. Geographic information system design for network equilibrium-based travel demand models.Transportation Research4C, 373-389.

[8] Jinsoo You, Tschangho John Kim, 1999. An integrated urban systems model with GIS. Geographical Systems. 1: 305-321.

[9] Keechoo Choi \& Tschangbo John Kim., 1996. A Hybrid Travel Demand Model With GIS and Expert Systems. Comput., Environ. and Urban Systems. Vol.20, No 4/5, 247-259.

[10] B.Harris, 1996. Land use Models in Transportation Planning: a review of past developments and current best practice, Delawae Valley Regional Plannning Commision, USA. 